\title{
Artur Bajerski
}

Uniwersytet im. Adama Mickiewicza w Poznaniu

Instytut Geografii Społeczno-Ekonomicznej i Gospodarki Przestrzennej

e-mail: bajerski@amu.edu.pl

\section{Student jako użytkownik miasta: brytyjskie doświadczenia studentyfikacji}

\begin{abstract}
Zarys treści: Celem artykułu jest dokonanie przeglądu oraz usystematyzowanie wyników prowadzonych w Wielkiej Brytanii prac badawczych poświęconych procesowi studentyfikacji. Studentyfikację zazwyczaj ujmuje się jako proces wieloaspektowych przemian miast akademickich, dokonujących się pod wpływem rosnącej i wysokiej liczby studentów. Ponieważ przekształcenia te zostały po raz pierwszy zidentyfikowane oraz skonceptualizowane właśnie przez brytyjskich badaczy na przełomie XX i XXI w., najlepiej rozpoznane są jego przebieg oraz formy w miastach akademickich Wielkiej Brytanii. W artykule kolejno omówiono (1) wymiary, w których zazwyczaj analizuje się proces studentyfikacji, (2) relacje studenci-stali mieszkańcy miasta, (3) rozmieszczenie miejsc zamieszkania studentów oraz ich koncentrację przestrzenną w miastach akademickich, (4) wpływ studentyfikacji na zróżnicowania społeczno-przestrzenne miast akademickich i sytuację na rynku nieruchomości.
\end{abstract}

Słowa kluczowe: studentyfikacja, studenci, użytkownik miasta, przekształcenia miast, Wielka Brytania

\section{Wprowadzenie}

Choć studenci wywierają wpływ na funkcjonowanie miast już od kilkuset lat (Brockliss 2000), dopiero w latach 90. XX w. zaczęto ich traktować jako istotnego aktora przemian ośrodków akademickich. Do najważniejszych konceptualizacji ujmujących wpływ studentów na miasta należą koncepcja użytkownika miasta autorstwa Martinottiego $(1996,2005)$ oraz pojęcie studentyfikacji, wprowadzone do literatury naukowej przez Smitha (2002). Wedle koncepcji użytkowników miasta studenci należą do tzw. trzeciej miejskiej populacji (pierwszą stanowią mieszkańcy miasta, drugą zaś osoby dojeżdżające ze strefy podmiejskiej), która obejmuje tzw. użytkowników miasta - mobilnych konsumentów przybywających do niego głównie w celu korzystania z oferowanych przez nie usług (sklepów, kin, muzeów, instytucji edukacyjnych itd.) i w związku z tym wywołujących w miastach szereg przekształceń. Powszechnie w literaturze anglosaskiej, ale również 
coraz częściej w literaturze $\mathrm{w}$ języku polskim, przekształcenia te określa się za Smithem (2002) mianem studentyfikacji (zob. Murzyn-Kupisz, Szmytkowska 2012, Jakóbczyk-Gryszkiewicz i in. 2014).

Procesy studentyfikacji zostały jak dotąd najgłębiej udokumentowane w odniesieniu do miast Wielkiej Brytanii, co wynika zarówno ze skali przekształceń brytyjskich miast pod wpływem studentów, jak i identyfikacji tego problemu najwcześniej przez brytyjskich badaczy. $Z$ tego względu procesy zachodzące $\mathrm{w}$ brytyjskich ośrodkach akademickich można uznać za podstawowy punkt odniesienia $\mathrm{w}$ badaniach nad studentyfikacją. Celem artykułu jest dokonanie przeglądu oraz próba usystematyzowania wyników prowadzonych w Wielkiej Brytanii prac badawczych poświęconych wpływowi studentów na miasta akademickie, ujmowanych pod wspólnym szyldem procesów studentyfikacji. W artykule kolejno omówiono: (1) podstawowe wymiary studentyfikacji, (2) specyfikę studentów jako użytkowników miasta, (3) rozmieszczenie miejsc zamieszkania oraz koncentrację przestrzenną studentów w mieście, (4) zróżnicowania społeczno-przestrzenne i zmiany na rynku nieruchomości pod wpływem studentyfikacji.

\section{Wymiary studentyfikacji}

Studentyfikacja jest zazwyczaj traktowana jako proces wielowymiarowy, ponieważ prowadzi do „wyraźnych społecznych, kulturowych, ekonomicznych i fizycznych przekształceń $\mathrm{w}$ miastach akademickich, które są powiązane $\mathrm{z}$ sezonową migracją studentów" (Smith 2004, s. 74) ${ }^{1}$. Jej zrozumienie wymaga więc prześledzenia przekształceń miast $\mathrm{w}$ ujęciu społecznym, kulturowym, ekonomicznym i fizycznym (przestrzennym).

$\mathrm{W}$ dotychczasowych pracach $\mathrm{w}$ wymiarze społecznym proces studentyfikacji wiąże się z wymianą ludności - na obszarach jej podlegających spada udział dotychczasowych stałych mieszkańców, rośnie zaś udział studentów. Prowadzi to do pojawiania się nowych mechanizmów segregacji społecznej w miastach, związanej ze wzrostem koncentracji przestrzennej studentów względem pozostałych kategorii mieszkańców (Chatterton 1999, 2010, Rugg i in. 2002, Allinson 2006, Smith 2009, Smith, Hubbard 2014). W wymiarze kulturowym poprzez studentyfikację rozumie się zazwyczaj upowszechnianie się studenckiego stylu życia (określonego wzorca zachowań konsumpcyjnych), które towarzyszy rosnącej na danym obszarze liczbie studentów (Smith 2004, 2005, Munro, Livingstone 2011, Sage i in. 2012). W wymiarze ekonomicznym studentyfikację ujmuje się zazwyczaj jako proces, który przejawia się w zmianach na rynku nieruchomości pod wpływem studentów (wzrost cen wynajmu nieruchomości oraz spadek udziału mieszkań zajmowanych przez ich właścicieli - Adams i in. 2009, Smith i Hubbard

Równocześnie należy zauważyć, że choć rosnąca koncentracja studentów w miastach akademickich staje się jednym z kluczowych procesów przekształceń miast, pojęcie studentyfikacji nie odnosi się jednak tylko do skali wewnątrzmiejskiej. W szerszym kontekście jako studentyfikację określa się również proces migracji studentów z miejsc stałego zamieszkania (głównie mniejszych miast i obszarów wiejskich) do ośrodków akademickich (por. Duke-Williams 2009). 
2014) oraz w przekształceniach struktury gospodarki miejskiej w skali ogólnomiejskiej (m.in. zwiększenie popytu i poziomu wydatków w gospodarce lokalnej, uelastycznienie rynku pracy - Universities UK 2006) i osiedlowej (np. rozwój sektora obsługi studentów - Chatterton 2010). W wymiarze fizycznym z kolei studentyfikacja wiąże się z przekształceniami infrastruktury mieszkaniowej. Wskazuje się, że może się ona poprawiać, co uzależnione jest od budowy nowych osiedli studenckich czy renowacji budynków i przystosowywania ich na potrzeby studentów, lub pogarszać - dotyczy to m.in. wspólnej infrastruktury osiedlowej na obszarach, na których rośnie udział studentów (studenci zazwyczaj nie troszczą się o nią tak, jak stali mieszkańcy - por. Smith 2004, 2005, Sage i in. 2012).

Przedstawione powyżej za Smithem (2004) cztery wymiary studentyfikacji z pewnością ułatwiają ukazanie złożoności zjawiska oraz różnorodności jego konsekwencji w różnych skalach przestrzennych. Należy mieć jednak na uwadze, że wydzielenie ich wynika $z$ bezpośredniego nawiązania do procesów gentryfikacji, badanych już wcześniej przez Smitha. $Z$ tym też może się wiązać niepełna ich rozłączność oraz nieco kontrowersyjne przyporządkowanie poszczególnych procesów do określonych wymiarów ${ }^{2}$.

\section{Studenci a mieszkańcy: specyfika studentów jako użytkowników miast}

W pracach poświęconych studentyfikacji często studentów stawia się w opozycji do stałych mieszkańców miasta, zakładając, że wiele problemów współżycia tych dwóch kategorii mieszkańców wynika ze specyfiki studentów.

Studenci zazwyczaj traktowani są jako relatywnie zamożni, kłopotliwi i hałaśliwi przybysze, utrudniający spokojne życie stałym mieszkańcom i będący dla nich zagrożeniem. Ta perspektywa oczywiście nie jest nowa, bowiem te problemy występowały już w średniowieczu (Brockliss 2000). Ze względu jednak na powszechność edukacji wyższej oraz na postindustrialne przemiany miast, związane $z$ dominującą rolą sektora usług, w tym szeroko pojmowanej sfery rozrywki oraz wypoczynku (zob. Chatterton, Hollands 2003, Valentine i in. 2008), dziś problemy te są bardziej dostrzegalne i powszechne niż w przeszłości. Uczestnictwo w rozrywce stało się istotnym „rytuałem socjalizacyjnym” młodych ludzi, silnie wiążącym się z kulturą młodzieżową, która w ostatnich kilkudziesięciu latach wyodrębniła się jako ważny aspekt formowania się ich tożsamości (Sande 1993, za Hollands 1995) ${ }^{3}$. Spożywanie alkoholu - w tym przez studentów - stało się $\mathrm{w}$ ostatnich latach jednym ze sposobów spędzania wolnego czasu, nie ogra-

$2 \quad$ Dla przykładu mianem wymiaru demograficznego można by w istocie określić opisany wcześniej wymiar społeczny, zaś mianem społecznego te procesy, które zaliczono do wymiaru kulturowego.

3 Rozpowszechnienie się kultury młodzieżowej w tym kontekście jest przejawem wyodrębnienia się wieku młodości jako osobnego ważnego okresu w życiu, który jest czymś więcej niż okresem przejściowym między dzieciństwem i dorosłością (por. Hollands 1995, Sibley 1995, Valentine i in. 1998). 
niczając się jak dawniej tylko do mężczyzn oraz ich rytuałów grupowych często powiązanych $z$ pracą (Valentine $i$ in. 2007). Zachodzące zmiany wpływały na narastanie konfliktu pomiędzy uczestnikami życia nocnego (m.in. studentami) a mieszkańcami, szczególnie centrów miast (Morgan 1997, Valentine i in. 2008).

Kolizja oczekiwań i codziennych praktyk studentów i mieszkańców nie studentów występuje jednak nie tylko $\mathrm{w}$ centrach miast, ale też $\mathrm{w}$ różnych dzielnicach mieszkaniowych. Wynika ona z różnic w postrzeganiu i wykorzystywaniu miejsca zamieszkania. O ile dla mieszkańców nie studentów miejsce zamieszkania zazwyczaj jest tylko częściowo przestrzenią rozrywki, o tyle dla studentów dom wydaje się „pełnoprawnym” miejscem rozrywki, na równi z klubami i pubami. Powszechnie zatem wysuwane są wobec studentów-sąsiadów zarzuty dotyczące hałasowania w późnych godzinach nocnych, a także, częściowo z tym powiązanego, braku dbałości o przestrzenie wspólne (por. Bromley 2006, Sage i in. 2012). Sami zaś studenci odbierani są przez nie studentów jako osoby, „których wartości i style życia nie zgadzają się z zasadami moralnymi wyznawanymi przez większość mieszkańców" (Hubbard 2008, s. 334). Postrzeganie studentów jako kategorii osób niedostosowanych społecznie do stałych mieszkańców miasta i konfliktogennych wiąże się z tym, że są oni osobami, które traktuje się jako wciąż „uczące się" dorosłości. Miasta akademickie służą im za „tymczasowe place zabaw” (ang. temporal playground), na których „uczenie się” dorosłości następuje poprzez wchodzenie w różne relacje ze stałymi mieszkańcami (Russo, Tatjer 2007). O tym, jakie napięcia wynikają ze współzamieszkiwania danego obszaru przez stałych mieszkańców miasta i wielu studentów, świadczą określenia pojawiające się w brytyjskich mediach (zarówno lokalnych, jak i ogólnokrajowych). Należy do nich choćby coraz popularniejszy termin „okupacja studencka” (por. Sage i in. 2012).

Jak wykazują m.in. badania Chattertona (1999), Holdsworth (2009), Holtona i Rileya (2014) oraz Smitha i Hubbarda (2014), „uczenie się” dorosłości przez studentów w brytyjskich miastach akademickich ma istotny wymiar przestrzenny. Studenci w Wielkiej Brytanii zazwyczaj najpierw są zakwaterowani w akademikach, dopiero później decydują się na zamieszkanie w mieszkaniach studenckich (tj. w mieszkaniach wynajętych wraz z innymi studentami). To przejście od „bezpiecznej przystani”, jaką jest akademik, do zamieszkiwania w quasi-gospodarstwach domowych interpretowane jest jako okres przejścia do dorosłości i pełnej niezależności. Wiąże się to często z zamieszkaniem w sąsiedztwie stałych mieszkańców miasta i powoduje wchodzenie $z$ nimi w rozmaite relacje (co rodzi czasem wspomniane wcześniej konflikty). Jak wskazują badania Holtona i Rileya (2014), kolejnym latom studiów oraz przenosinom do mieszkań studenckich, towarzyszy nierzadko głębsza zmiana oczekiwań i preferencji studentów. Ponieważ preferencje te w pewnym stopniu zbliżają się do preferencji stałych mieszkańców miasta, studentom coraz mniej zaczyna odpowiadać życie w swoistej „bańce studenckiej”, którą tworzy np. kampus uniwersytecki ze zlokalizowanymi na nim budynkami uczelnianymi, akademikami, klubami itd. Pomimo więc dominującego w literaturze przedmiotu stawiania studentów w opozycji do stałych mieszkańców miasta, kolejne lata studiów oraz nawet konflikty z mieszkańcami sprawiają, że studen- 
ci pod względem preferencji spędzania wolnego czasu oraz miejsca zamieszkania upodabniają się stopniowo do dorosłych mieszkańców nie studentów.

\section{Rozmieszczenie miejsc zamieszkania oraz koncentracja przestrzenna studentów w mieście}

Kluczowym zagadnieniem w badaniach nad procesami studentyfikacji jest rozmieszczenie miejsc zamieszkania studentów. Identyfikacja tych miejsc stanowi zazwyczaj zarówno podstawę analiz koncentracji i segregacji społecznej związanych ze studentyfikacją, jak i główną warstwę odniesienia przy próbach zrozumienia zachowań przestrzennych studentów w mieście.

Dotychczasowe wyniki badań brytyjskich badaczy wykazywały dość oczywistą prawidłowość, że studenci mieszkają przede wszystkim na kampusach, w ich pobliżu lub też w centrum miasta (Rugg i in. 2000, 2002, Smith 2005). Wynika to w szczególności z ich preferencji mieszkaniowych oraz możliwości finansowych. Jak wykazały badania Allinsona (2006), brytyjscy studenci kierują się w swych wyborach mieszkaniowych głównie odległością od uczelni oraz - choć w mniejszym stopniu - odległością od centrum miasta. Dodatkowo na wybór miejsca zamieszkania wpływa m.in. położenie transportowe czy względy bezpieczeństwa. W Wielkiej Brytanii ważnym czynnikiem wyboru miejsca zamieszkania jest także odczuwana przez studentów „studenckość poszczególnych obszarów” (Smith, Holt 2004, za Sage i in. 2012). Ze względu na zazwyczaj dobrą sytuację finansową brytyjskich rodzin oraz powszechny dostęp do kredytów studenckich, w niewielkim stopniu na wybór miejsca zamieszkania wpływa cena wynajmu mieszkania (różni to w znacznym stopniu studentów w Wielkiej Brytanii od studentów w Polsce) ${ }^{4}$.

Mając na uwadze wskazane wyżej, typowe dla miast akademickich Wielkiej Brytanii, zamieszkiwanie studentów w pobliżu kampusów uniwersyteckich i centrów miast, należy stwierdzić, że nie zaskakują wyniki dotychczasowych badań, które wskazują, że studenci w brytyjskich miastach są silniej skoncentrowani przestrzennie niż nie studenci (Munro i in. 2009). Sytuacja ta była już dostrzegana przez badaczy pod koniec XX w. W 1999 r., identyfikując wysoką koncentrację studentów na wybranych obszarach Bristolu, Chatterton (1999) opisał proces tworzenia się przestrzeni przeznaczonych zasadniczo tylko dla potrzeb studentów (obszary koncentracji zamieszkania oraz rozrywki studentów). Obszary takie są określane mianem enklaw studenckich, niekiedy zaś nawet „studenckich gett”. Jak podają Munro i in. (2009), wielkości i liczba enklaw studenckich oraz stopień koncentracji przestrzennej studentów w brytyjskich miastach akademickich rosną zwykle wraz z liczbą studentów w mieście akademickim. Dokumentują to wyniki badań Smitha

\footnotetext{
W ostatnich latach obserwuje się jednak wzrost udziału, jak to określają brytyjscy badacze, studentów nietradycyjnych (ang. non-traditional students), tj. m.in. studentów wywodzących się z rodzin nie należących do klasy średniej (ale także np. studiujących w miejscu stałego zamieszkania), którzy częściej kierują się w swych wyborach kryteriami finansowymi (por. Christie 2007, Holton, Riley 2013).
} 
i Hubbarda (2014), którzy zidentyfikowali w Anglii i Walii ponad 30 osiedli (części miast - ang. wards), w których udział studentów dziennych, mieszkających $\mathrm{w}$ tzw. mieszkaniach studenckich, przekraczał $20 \%$ ogółu ludności (w tym na 8 osiedlach udział studentów był wyższy niż 30\%, zaś na 2 przekraczał nawet $40 \%$ ).

\section{Zróżnicowania społeczno-przestrzenne i zmiany na rynku nieruchomości wywołane studentyfikacją}

Silna koncentracja studentów w określonych obszarach miasta ma konkretne implikacje dla rynku mieszkaniowego i szerzej dla społecznej geografii miast akademickich. Jak zauważają Smith i Hubbard (2014), implikacje te wykraczają poza czysto ekonomiczną perspektywę, związaną ze wzrostem cen mieszkań na najbardziej „ustudentowionych” terenach. Przykładem jest choćby to, że wzrost cen nieruchomości w rejonie, w którym rośnie liczba studentów, wpływa ograniczająco na możliwości zakupu mieszkania przez inne kategorie mieszkańców, w tym np. rodziny z dziećmi (Adams i in. 2009, Smith, Hubbard 2014). Dodatkowo, wskazywane już wyżej i uznawane za uciążliwe niektóre elementy stylu życia studentów oraz dokonujące się wraz ze wzrostem udziału studentów przeobrażenia wyposażenia usługowego okolic ich zamieszkania (Chatterton 2010), mogą być kolejnym czynnikiem odpływu dotychczasowych mieszkańców z obszarów podlegających intensywnej studentyfikacji. Badania Rugg i in. (2012) wykazały, że rosnący udział studentów wśród ogółu mieszkańców i wśród wynajmujących mieszkania może prowadzić też do destabilizacji rynku wynajmu poprzez zorientowanie go przede wszystkim na potrzeby studentów, marginalizując inne potencjalne kategorie wynajmujących.

W kontekście procesów prowadzących do podziałów społeczno-przestrzennych $\mathrm{w}$ miastach akademickich często wiąże się studentyfikację z gentryfikacją. W ogólnym ujęciu, jak wskazał Smith (2005), zakresy obu pojęć częściowo się pokrywają, oba bowiem dotyczą różnoskalowych i wielowymiarowych zmian dokonujących się w miastach $w$ warunkach napływu specyficznej kategorii społecznej osób na określone jego obszary ${ }^{5}$. Zazwyczaj brytyjscy badacze wskazują, że studenci, z których znaczna część wywodzi się z rodzin klasy średniej oraz wyższej, napływają na tereny podlegające gentryfikacji i zamieszkiwane przez klasę średnia, czyli w uproszczeniu, jak ujął to Chatterton (2010), przez ludzi takich jak oni sami (w kontekście klasy, z której się wywodzą). Wskazuje się również, że studentyfikacja jest procesem poprzedzającym zajście właściwych procesów gentryfikacji na danym obszarze (Bridge 2006). Równocześnie zwraca się uwagę, jak podkreśla Smith (2005), że studentyfikacja nie jest procesem tak złożonym i zachodzącym w tak dużej skali, jak gentryfikacja. Prowadzone przez brytyjskich badaczy w ostatnich latach analizy dowiodły, że na niektórych obszarach napływ studentów nie może być uznany za początek czy też zwiastun gentryfikacji. Wręcz

5 Podobieństwo obu procesów wyrażają także, przytoczone za Smithem (2004), cztery płaszczyzny, na których zachodzą zarówno procesy studentyfikacji, jak i gentryfikacji. 
odwrotnie, napływ studentów może prowadzić do rosnącego przekonania mieszkańców o postępującej marginalizacji tych dzielnic. Dotyczy to zazwyczaj części miast już stygmatyzowanych jako zmarginalizowane, zamieszkanych przez ludność reprezentującą niższe warstwy społeczne, do których migrują studenci, często wywodzący się spoza klasy średniej (Sage i in. 2012).

Nie mniej zauważany przez brytyjskich badaczy niż związek studentyfikacji z gentryfikacją, jest jej związek z procesami rewitalizacji, w szczególności z zagospodarowywaniem obszarów poprzemysłowych. W ostatnich latach w niektórych brytyjskich miastach uniwersyteckich to właśnie miejskie obszary poprzemysłowe były obszarami spektakularnych inwestycji w zabudowę mieszkaniową adresowaną do studentów - powstają na nich całe luksusowe osiedla studenckie (ang. exclusive purpose build student accomodation - zob. Chaterton 2010, Smith, Hubbard 2014). Jak podają Smith i Hubbard (2014), na tych terenach zazwyczaj nie ma osób, które by mieszkały tam wcześniej, a zatem nie dochodzi do wypierania dotychczasowych mieszkańców przez studentów. Mimo tego, jak wskazują autorzy, budowa tego typu osiedli istotnie wpływa na lokalny rynek nieruchomości. Wiąże się to m.in. ze znacznym zainteresowaniem brytyjskich studentów zamieszkiwaniem w takich osiedlach, ponieważ „oferują” one inne doświadczenie życia studenckiego niż bardziej tradycyjne formy zakwaterowania w okresie studiów (Chatterton 2010). Jak wskazują Smith i Hubbard (2014), takie inwestycje są szczególnie „przyjazne studentom” (and. student friendly), ponieważ powstały $\mathrm{w}$ celu spełniania oczekiwań związanych $\mathrm{z}$ ich stylem życia. We wspomnianych obiektach znajduje się od kilkuset do nieraz nawet kilku tysięcy miejsc dla studentów. Ich położenie $z$ dala od istniejącej zabudowy mieszkaniowej minimalizuje z kolei uciążliwości sąsiedztwa studentów dla stałych mieszkańców, a zarazem uciążliwości sąsiedztwa stałych mieszkańców dla studentów (Hubbard 2009, Chatterton 2010, Smith, Hubbard 2014). Powstawanie takich osiedli studenckich, pomimo potencjalnego pozytywnego wpływu na zmniejszanie konfliktów pomiędzy studentami i stałymi mieszkańcami, może istotnie przyczyniać się do wzrostu poziomu segregacji społeczno-przestrzennej w miastach akademickich. Może również negatywnie wpływać na proces „uczenia się” dorosłości przez studentów przyjeżdżających na studia, ze względu na wypieranie innych form zamieszkania studentów, $w$ tym przede wszystkim zamieszkiwania $\mathrm{w}$ wynajmowanych mieszkaniach w otoczeniu nie studentów.

\section{Zakończenie}

Przedstawione $\mathrm{w}$ artykule wyniki badań brytyjskich badaczy potwierdzają, na co zwrócono uwagę już we wstępie artykułu, że studentyfikacja jest procesem wielowymiarowym. $Z$ jednej strony może być traktowana jako czynnik rozwoju miast, $z$ drugiej zaś jako zagrożenie ich rozwoju, przekształcając miasta akademickie w miejsca coraz mniej atrakcyjne do życia dla mieszkańców nie studentów. Nie powinno zatem dziwić, że w Wielkiej Brytanii studentyfikacja jest problemem, znajdującym się w centrum zainteresowania wielu społeczności lokalnych, urzę- 
dów miast i władz uczelnianych (por. Universities UK 2006, Sage i in. 2011). Coraz częściej proces studentyfikacji traktuje się w tym kraju jako strategiczne wyzwanie w zarządzaniu miastami akademickimi, dlatego opracowuje się programy strategiczne mające na celu minimalizowanie negatywnych efektów studentyfikacji (głównie niekontrolowanego rozprzestrzeniania się studentów w mieście oraz konfliktów studentów z mieszkańcami nie studentami) oraz maksymalizowanie efektów pozytywnych (m.in. regeneracja zaniedbanych dzielnic, w tym obszarów poprzemysłowych). Przykłady takich działań były wskazywane już w 2006 r. W raporcie "«Studentification»: a guide to opportunities, challenges and practice” (Universities UK 2006). Podkreślano w nim, że skuteczność działań ukierunkowanych na kontrolę procesu studentyfikacji zależy od współpracy głównych aktorów lokalnych, mogących oddziaływać na rozmieszczenie studentów w mieście i ich zachowania, tj. władz miejskich, rad osiedli oraz władz uczelni wyższych. Świadomość problemów dotyczących studentyfikacji i możliwości ich rozwiązywania wydaje się szczególnie istotna $\mathrm{w}$ kontekście rosnącej liczby doniesień o kłopotach wynikających z koegzystencji studentów i nie studentów w ośrodkach akademickich w Polsce.

\section{Literatura}

Adams D., Leishman C., Moore C. 2009. Why not build faster? Explaining the reluctance of UK housebuilders to speed up supply of new homes for owner occupation. Town Planning Review, 80: 291-314.

Allinson J. 2006. Over-educated, over-exuberant, and over there? The impact of students on cities Planning. Practice and Research, 21: 79-94.

Bridge G. 2006. It's not just a question of taste: Gentrification, the neighbourhood, and cultural capital. Environment and Planning A, 38: 1965-1978.

Brockliss L. 2000. Gown and Town: the University and the City in Europe, 1200-2000. Minerva, 38: $147-170$.

Bromley R. 2006. On and off campus: Colleges and universities as local stakeholders. Planning, Practice \& Research, 21: 1-24.

Chatterton P. 1999. University students and city centres - the formation of exclusive geographies. The case of Bristol, UK. Geoforum, 30: 117-133.

Chatterton P. 2010. The student city: an ongoing story of neoliberalism, gentrification, and commodification. Environment and Planning A, 42: 509-514.

Chatterton P., Hollands R. 2003. Urban nightscapes: youth cultures, pleasure spaces and corporate power. Routledge, London.

Christie H. 2007. Higher education and spatial (im)mobility: nontraditional students and living at home. Environment and Planning A, 39: 2445-2463.

Duke-Williams O. 2009. The geographies of student migration in the UK. Environment and Planning A, $41: 1826-1848$.

Holdsworth C. 2009. Going away to uni? Mobility, modernity and independence of English higher education students. Environment and Planning A, 41: 1849-1864.

Hollands R. 1995. Friday night, Saturday night: youth cultural identity in the post industrial city (http://research.ncl.ac.uk/youthnightlife/HOLLANDS.PDF; dostęp: 3.03.2015).

Holton M., Riley M. 2013. Student geographies: Exploring the diverse geographies of students and higher education. Geography Compass, 7: 61-74.

Holton M., Riley M. 2014. Talking on the move: place-based interviewing with undergraduate students. Area, 46: 59-65. 
Hubbard P. 2008. Regulating the social impact of studentification: A Loughborough case study. Environment and Planning A, 40: 323-341.

Hubbard P. 2009. Geographies of studentification and purpose-built student accommodation: leading separate lives? Environment and Planning A, 41: 1903-1923.

Jakóbczyk-Gryszkiewicz J., Marcińczak S., Wolaniuk A. 2014. Gentrification processes in the city. [W:] T. Marszał (red.), Society and Space in Contemporary Poland in Łódź University Geographical Research. University of Łódź, Lódź, s. 83-111.

Martinotti G. 1996. Four populations: Human settlements and social morphology in the contemporary metropolis. European Review, 4: 3-23.

Martinotti G. 2005. Social morphology and novernance in the new metropolis. [W:] Y. Kazepov (red.), Cities of Europe: Changing Contexts, Local Arrangement and the Challenge to Urban Cohesion. Blackwell Publishing Ltd, Malden-Oxford-Carlton, s. 90-108.

Morgan S. 1997. Cheap drinks, heavy costs: students and alcohol. Youth and Policy, 56: 42-55.

Munro M., Turok I., Livingston M. 2009. Students in cities: a preliminary analysis of their patterns and effects. Environment and Planning A, 41: 1805-1825.

Munro M., Livingston M. 2011. Student impacts on urban neighbourhoods: policy approaches, discourses and dilemmas. Urban Studies, 49: 1679-1694.

Murzyn-Kupisz M., Szmytkowska M. 2012. Procesy studentyfikacji w przestrzeni polskich miast na przykładzie Krakowa i Trójmiasta. [W:] J. Jakóbczyk-Gryszkiewicz (red.), Procesy gentryfikacji w mieście. Cz. I. XXV Konwersatorium Wiedzy o Mieście. Wydawnictwo Uniwersytetu Łódzkiego, Łódź, s. 57-70.

Rugg J., Rhodes D., Jones A. 2000. The nature and impact of student demand on housing markets. York Publishing Services Ltd, Layerthorpe.

Rugg J., Rhodes D., Jones A. 2002. Studying a niche market: UK students and the private rented sector. Housing Studies, 17: 289-303.

Russo A.P., Tatjer L.C. 2007. From citadels of education to cartier latins (and back?): the changing landscapes of student populations in European cities. Geography Compass, 1: 1160-1189.

Sande A. 1994. The Use of Alcohol in the Ritual Process. Norlands Research Institute, Bodo (materiat niepublikowany).

Sage J., Smith D., Hubbard P. 2011. The rapidity of studentification and population change: there goes the (student)hood. Population, Space and Place, 18: 597-613.

Sage J., Smith D., Hubbard P. 2012. The diverse geographies of studentification: Living alongside people not like us. Housing Studies, 27: 1057-1078.

Sibley D. 1995. Geographies of Exclusion. Routledge, London.

Smith D.P. 2002. Patterns and processes of studentification in Leeds. Regional Review, 1: 14-16.

Smith D.P. 2004. Geographies of studentification and apprentice gentrifiers, artykuł zgłoszony na 7th Pan-Hellenic Geographical Conference of the Hellenic Geographical Association, University of Lesvos, Greece (http://srcosmos.gr/srcosmos/showpub.aspx?aa=6348; dostęp: 12.02.2015).

Smith D.P. 2005. Studentification: the gentrification factory. [W:] R. Atkinson, G. Bridge (red.), Gentrification in a Global Context. Routledge, London, s. 72-89.

Smith D.P. 2009. 'Student geographies', urban restructuring, and the expansion of higher education. Environment and Planning A, 41: 1795-1804.

Smith D.P., Holt L. 2004. Processes and Patterns of Studentification in Brighton and Eastbourne: A Report to the Vice Chancellors Office. University of Brighton, Brighton.

Smith D.P., Hubbard P. 2014. The segregation of educated youth and dynamic geographies of studentification. Area, 46: 92-100.

Universities UK 2006. 'Studentification': a guide to opportunities, challenges and practice. Universities UK, London.

Valentine G., Holloway S., Knell C., Jayne M. 2007. Drinking places. Where people drink and why. Joseph Rowntree Foundation, York.

Valentine G., Holloway S., Knell C., Jayne M. 2008. Drinking places: Young people and cultures of alcohol consumption in rural environments. Journal of Rural Studies, 24: 28-40.

Valentine G., Skelton T., Chambers D. 1998. Cool places: an introduction to youth and youth cultures. [W:] T. Skelton, G. Valentine (red.), Cool Places. Geographies of Young Culture. Routledge, London, New York, s. 1-32. 


\section{A Student as a city user: British experience}

Abstract: This paper seeks to survey and systematise the results of a research conducted in Great Britain on studentification. Studentification is usually treated as a process of multi-aspect changes of academic towns that occur under the influence of the ever growing and high number of students. Since it was British scholars who were the first to identify and conceptualise this process at the close of the 20th and the beginning of the 21st centuries, its pattern and forms have best been recognised in the academic towns of Great Britain. The article discusses: (1) aspects in terms of which the studentification process is usually analysed, (2) relations between students and permanent inhabitants, (3) the distribution of students' places of residence and their spatial concentration in academic towns, and (4) the effect of studentification on the socio-spatial diversification of academic towns and the situation on the real-estate market.

Key words: Studentification, students, city users, urban change, Great Britain 